Marc Beaussier MD, Hugues Deriaz MD, Zoubida Abdelahim MD, Feti Aissa MD, André Lienhart MD

\title{
Comparative effects of desflurane and isoflurane on recovery after long lasting anaesthesia
}

Purpose: Increasing the duration of exposure could lead to amplification of the pharmacokinetic differences between halogenated anaesthetic agents. The aim of our study was to compare anaesthesia recovery after desflurane and isoflurane, administered for more than three hours.

Methods: After informed consent, patients were randomly assigned to either desflurane $(n=15)$ or isoflurane $(n=15)$ groups. At the end of surgery, halogenated agents were discontinued and fresh gas flow was increased to $6 \mathrm{I} \cdot \mathrm{min}^{-1}$ oxygen $100 \%$.

Results: Mean anaesthesia duration was $292 \pm 63$ and $304 \pm 91 \mathrm{~min}$ in the desflurane and isoflurane groups respectively. After desflurane and isoflurane discontinuation, the time to opening eyes was $12 \pm 7$ and $24 \pm 11$ min respectively $(P<0.001)$; to squeeze fingers at command was $17 \pm 11$ and $35 \pm 19 \min (P<0.001)$; to extubation was $16 \pm 6$ and $33 \pm 13 \min (P<0.001)$; to give their name was $22 \pm 12$ and $43 \pm 21 \min (P<0.001)$; to achieve a Steward score of 6 was $28 \pm 16$ and $57 \pm 33 \min (P<0.001)$, to be fit for discharge from the recovery room was $46 \pm 19$ and $81 \pm 37 \mathrm{~min}(P<0.003)$. Ranges of times to reappearance of recovery variables in the desflurane group were less than those after isoflurane $(P<0.05)$.

Conclusion: After long duration anaesthesia lasting up to three hours, desflurane allowed recovery and extubation in approximately half the time required by isoflurane. Less variability in results suggests better predictability of recovery with desflurane.

Objectif : Les différences pharmacodynamiques entre les agents halogénés sont amplifiées par la durée d'administration. Ce travail compare les paramètres de réveil après une anesthésie supérieure à trois heures avec de l'iso-flurane ou du desflurane.

Méthode : Après consentement éclairé, les patients ont été répartis par tirage au sort pour recevoir de l'isoflurane $(n=15)$ ou du desflurane $(n=15)$. Au dernier point de suture cutanée, l'administration d'agent halogéné était stoppée et le débit de gaz frais porté à $61 \cdot \mathrm{min}^{-1}$ d'oxygène.

Résultats : La durée d'anesthésie a été de $292 \pm 63$ et $304 \pm 91$ min pour le desflurane et l'isoflurane respectivement. Le délai pour l'ouverture des yeux a été de $12 \pm 7$ et $24 \pm 11 \mathrm{~min}(P<0.001)$; pour serrer les mains à la demande de $17 \pm 11$ et $35 \pm 19 \min (P<0.001)$; pour l'extubation de $16 \pm 6$ et $33 \pm 13 \min (P<0.001)$; pour donner son nom de $22 \pm 12$ et $43 \pm 21 \min (P<0.001)$; pour récupérer un score de Steward à 6 de 28 \pm 16 et $57 \pm 33 \mathrm{~min}(P<0.001)$; pour avoir l'autorisation de sortie de salle de réveil de $46 \pm 19$ et $81 \pm 37 \mathrm{~min}$ $(P<0.003)$ pour le desflurane et l'isoflurane respectivement.

Conclusion : Après une anesthésie supérieure à trois heures, le desflurane permet un réveil et une extubation approximativement deux fois plus rapide que l'isoflurane. La plus faible variabilité des valeurs suggère une meilleure prédictibilité des paramètres de réveil avec le desflurane.

From the Département d'Anesthésie-Réanimation chirurgicale, Hôpital St-Antoine, 184 rue du Fg St-Antoine, 75571 Paris Cédex 12, France. Supported by a grant from Pharmacia France, St Quentin-Yvelyne, France.

Address correspondence to: Dr. Marc Beaussier; Phone: 33-1-4928-2000; Fax: 33-1-4928-2826.

Accepted for publication January 31, 1998. 
$\mathrm{T}$

HE new volatile anaesthetic agent desflurane has the lowest blood-gas partition coefficient of the available halogenated agents. ${ }^{1}$ This low blood solubility suggests a potential for rapid recovery after discontinuation. ${ }^{1,2}$ Spectroscopic methods with magnetic resonance confirm the 1.7 times faster cerebral elimination of desflurane than of isoflurane. ${ }^{3}$ In the clinical setting, this pharmacokinetic property, leading to faster recovery after discontinuation, has been demonstrated both in animal ${ }^{4}$ and in human studies. ${ }^{5}$ Previous clinical reports pointed out the rapid recovery of consciousness and psychomotor function after short duration desflurane anaesthesia. ${ }^{6-20}$ This makes desflurane a suitable agent for day care surgery. However, the clinical advantage in decreasing time to awakening for a few minutes remains doubtful. ${ }^{20}$

Increased duration of anaesthesia may amplify pharmacokinetic profile differences between halogenated agents of different solubilities. The amount of anaesthetic taken up by body tissue is related both to agent solubility and to the duration of exposure. ${ }^{2}$ However, recovery after long duration surgical procedures is influenced by other factors, unrelated to the characteristics of the halogenated agent, such as high opioid concentration and residual neuromuscular blockade. Furthermore, hypothermia is common after long duration anaesthesia, especially during abdominal surgery. ${ }^{21}$ This could lead the physician to prolong sedation in the immediate postoperative period and thus delay recovery until rewarming is achieved..$^{21}$ In this circumstance, the advantages of the pharmacokinetic properties of rapidly eliminated agents like desflurane are offset.

The aim of this study was to compare the timing and quality of recovery after desflurane or isoflurane anaesthesia, in patients undergoing long duration abdominal surgery and in whom intraoperative skinsurface rewarming was performed.

\section{Patients and methods}

This study was approved by the Hospital Ethics Committee. Patients scheduled for abdominal surgical procedure lasting at least three hours gave their written informed consent.

\section{Study population}

We studied 30 patients aged between 18 and $70 \mathrm{yr}$ and ASA physical status I or II. Operations included left hemicolectomy $(\mathrm{n}=14)$, total intra-abdominal colectomy $(n=6)$, right hemicolectomy $(n=2)$, biliary tract anastomosis $(n=1)$, partial pancreatectomy $(n=2)$, reclosure of postoperative abdominal wall disruption $(n=1)$, oesoph- agogastroplasty $(n=1)$, repair of rectal prolapse $(n=1)$, abdomino perineal $(n=1)$ and ovarian resection $(n=1)$. Exclusion criteria included previous history of anaesthetic accident or abnormal delay of recovery, previous personal or family history of malignant hyperthermia, known allergy to anaesthetic drugs, fever (temperature $>38.5^{\circ} \mathrm{C}$ ), weight $>130 \%$ or $<80 \%$ of the ideal weight defined by Lorentz's formula (Appendix I), haematocrit $<25 \%$, drug or alcohol abuse, exposure to general anaesthesia with a duration up to one hour within seven days of the study, and electrocardiographic abnormality indicative of myocardial ischaemic disease.

\section{Anaesthetic procedure}

Patients were premedicated with $100 \mathrm{mg}$ hydroxyzine po one hour before surgery. Anaesthesia was induced with 4-7 $\mathrm{mg} \cdot \mathrm{kg}^{-1}$ thiopentone, $2-3 \mu \mathrm{g} \cdot \mathrm{kg}^{-1}$ fentanyl and $0.5-0.6 \mathrm{mg} \cdot \mathrm{kg}^{-1}$ atracurium. Tracheal intubation was performed in all patients. After induction, the patients were equipped with a hot air warming system (Bair Hugger ${ }^{\mathrm{TM}}$, Augustine Medicale, Mineapolis USA). Anaesthesia was maintained with a halogenated agent (isoflurane or desflurane) in a mixture of nitrous oxide $50 \%$ and oxygen $50 \%$ in a rebreathing circuit at $11 \cdot \mathrm{min}^{-1}$ fresh gas flow. Additionnal bolus fentanyl was administered just before skin incision (2-3 $\left.\mu \mathrm{g} \cdot \mathrm{kg}^{-1}\right)$, and during the operative period at the discretion of the physician (1-2 $\left.\mu \mathrm{g} \cdot \mathrm{kg}^{-1}\right)$. Continuous infusion of $0.5 \mathrm{mg} \cdot \mathrm{kg}^{-1} \cdot$ hour $^{-1}$ atracurium provided myorelaxation for good surgical conditions. This infusion was discontinued at least half an hour before the expected end of the surgery.

\section{Study protocol}

At the time of anaesthetic induction, patients were given a number in accordance with the randomisation list. Fifteen patients received isoflurane and the others received desflurane for anaesthetic maintenance. The end-tidal concentration of the inhalational anaesthetic allowed an adequate level of anaesthesia and blood pressure stability, defined by the lack of fluctuation of $>20 \%$ compared with a reference systolic blood pressure measured before induction.

Before discontinuation of anaesthesia, the need for reversal of muscle relaxation was determined by double-burst-stimulation of the thumb's adductor. If the response was insufficient, residual neuromuscular block was antagonised with $0.045 \mu \mathrm{g} \cdot \mathrm{kg}^{-1}$ neostigmine and $0.015 \mu \mathrm{g} \cdot \mathrm{kg}^{-1}$ atropine.

At the end of surgery (last suture of the skin), the anaesthetic and nitrous oxide were discontinued and the fresh gas flow rate was increased to $61 \cdot \mathrm{min}^{-1}$ oxygen $100 \%$. The time of discontinuation of the anaes- 


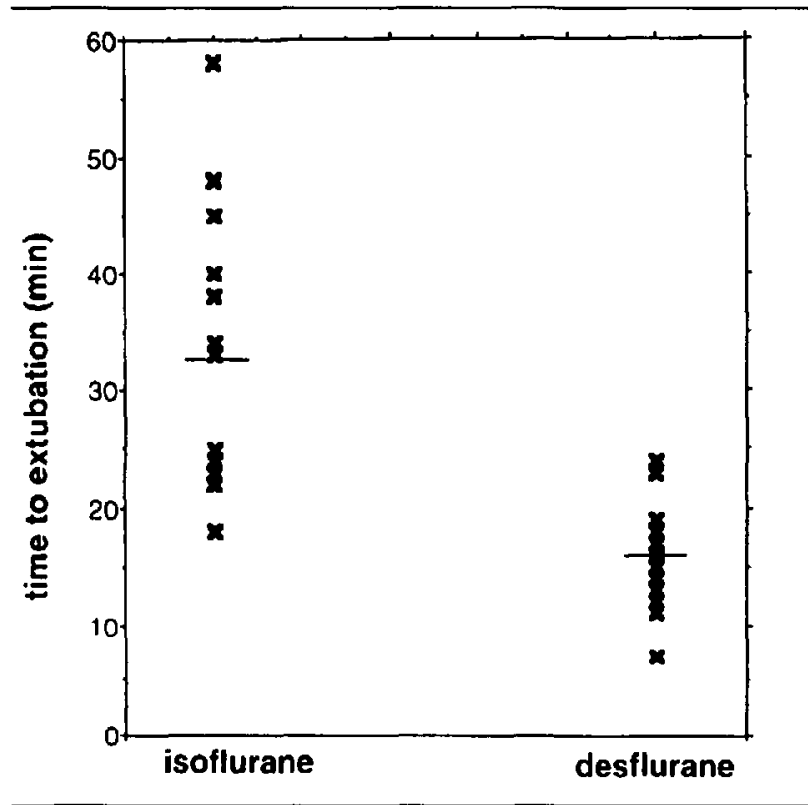

FIGURE I Time between end of anaesthetic administration and tracheal extubation

Several patients could be represented by the same cross. Horizontal lines correspond to mean values. The time to extubation after anaesthetic discontinuation was earlier with desflurane than with isoflurane $(P<0.001)$. Variability of values was less with desflurane than with isoflurane $(P<0.05)$.

thetic was recorded and was the baseline for the evaluation of the recovery process.

After reversal, and if the patient was judged able to maintain normocapnia, controlled ventilation was switched to spontaneous breathing. Extubation criteria were spontaneous breathing rate $<25 \cdot \mathrm{min}^{-1}$, pulse oxymetry $>95 \%$ breathing room air and intolerance to orotracheal tube.

\section{Study parameters}

Intraoperatively, patients were monitored by ECG, automated blood pressure cuff, pulse oximeter $\left(\mathrm{SpO}_{2}\right)$, end-tidal $\mathrm{CO}_{2}$ monitor $\left(\mathrm{P}_{\mathrm{ET}} \mathrm{CO}_{2}\right)$, tympanic temperature probe and inhalational agent monitor. The baseline values of systolic and diastolic blood pressure, heart rate, $\mathrm{SpO}_{2}$ and tympanic temperature were collected prior to induction and every 15 min during anaesthesia. The temperature of the operating room was measured with a second thermocouple probe placed near the head of the patient and collected at the beginning and at the end of surgery. The room temperature was kept at $20 \pm 1^{\circ} \mathrm{C}$.

At the end of surgery, the patients were placed in the recovery room and the following parameters were collected by observers not informed about the halogenated agent the patient received:

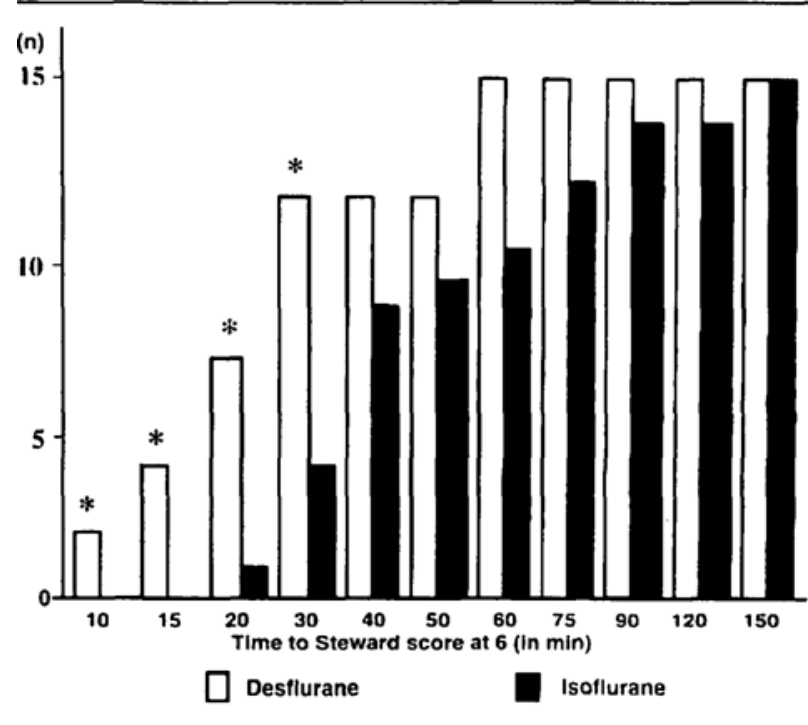

FIGURE 2 Number of patients with a Steward score at $6(\mathrm{n})$, as a function of time after discontinuation of desflurane and isoflurane.

*different from isoflurane group.

- The time of extubation

- The time when the patient opened his/her eyes after the question "open your eyes" repeated every $30 \mathrm{sec}$.

- The time when the patient was able to respond to specific commands ("squeeze my fingers," "what is your name?").

We recorded:

- Steward score 22 (Appendix II)

- Blood pressure, heart rate and $\mathrm{SpO}_{2}$

- Tympanic temperature

every five minutes for $20 \mathrm{~min}$, then every $10 \mathrm{~min}$ for $40 \mathrm{~min}$, finally every $15 \mathrm{~min}$ until the decision was made to remove the patient from the recovery room. Patients were judged fit for discharge from the recovery room if the Steward's score was 6 for three consecutive assessments.

The end tidal concentration of inhalational agent at the end of administration and throughout anaesthesia were recorded. Total consumption of halogenated agents was estimated with the area under the curve of end-tidal concentration throughout the course of the procedure and expressed as MAC fraction.

All intraoperative and postoperative intercurrent events, including haemodynamic events, nausea, vomiting and shivering were noted.

Shivering was assessed by clinical observation (severe shivering) or occurence of an irregular baseline ECG trace (moderate shivering). 


\section{Statistical analysis}

Statistical analysis used Student's $t$ test. Time for Steward's score to 6 in the two groups was compared with Chi-squared analysis or Fisher exact test when appropriate. Comparison of variance ( $F$ score) was used to estimate difference in variability between the results of recovery time in the two groups. A $P$ value $<0.05$ was considered statistically significant. Data are expressed as mean $\pm \mathrm{SD}$.

\section{Results}

The two groups were comparable with respect to sex, age, weight, anaesthesia duration and total fentanyl dose used (Table I). Consumption of halogenated agents during the procedure (expressed in mean \% end-tidal concentration $\left.\cdot \mathrm{hr}^{-1} \cdot \mathrm{MAC}^{-1}\right)$ were $2.8 \pm 0.6$ and $3.6 \pm \mathrm{l}$ for desflurane and isoflurane respectively $(P<0.05)$. End-tidal concentrations at the end of administration, expressed as fractionnal MAC, ${ }^{23,24}$ were $0.75 \pm 0.15$ and $0.62 \pm 0.2$ and did not differ between the two groups.

Intraoperative and postoperative haemodynamic patterns were identical between the two groups. The $\mathrm{P}_{\mathrm{ET}} \mathrm{CO}_{2}$ followed the pattern in the two groups and no oxygen capillary desaturation occured in any patient. In all patients, tracheas were extubated in the recovery room.

After discontinuation, time to opening eyes, to respond to command, to give name, to tracheal extubation and to Steward score at 6 occured earlier with desflurane than with isoflurane (Table II, Figures 1, 2).

Time to fitness for discharge from the recovery room was $46 \pm 19 \mathrm{~min}$ and $81 \pm 37 \mathrm{~min}$ in desflurane and isoflurane groups respectively $(P=0.003)$. Time for effective discharge was $88 \pm 36 \mathrm{~min}$ and $117 \pm 69 \mathrm{~min}$ in desflurane and isoflurane groups respectively $(P=0.47)$.

The magnitude of variability of values for all recovery variables, time to achieve a Steward's score of 6 and time to fitness for discharge from the recovery room were less for desflurane than for isoflurane $(P<0.05)$.

Tympanic temperature on arrival in the recovery room did not differ between the two groups and the rewarming procedure was effective in reducing intraoperative heat loss (Table III). There were no differences in shivering occurence, duration and severity between the two groups (Table III). There were no differences between the two groups with regard to postoperative nausea (nausea occured in two patients in the desflurane group).

\section{Discussion}

Our results demonstrate that time to emergence, time to extubation, time to respond to commands and time to be fitness for discharge from the recovery room with desflurane were approximatively half those with isoflurane after exposure for more than three hours in intraoperative warmed patients.
TABLE I Demographic data, duration af anaesthesia, end-tidal concentration at the end of surgery (ET\%) and total fentanyl dose for the two groups.

\begin{tabular}{llllll}
\hline & $\begin{array}{l}\text { sex } \\
F / M\end{array}$ & $\begin{array}{l}\text { weight } \\
(\mathrm{kg})\end{array}$ & $\begin{array}{l}\text { age } \\
(\mathrm{yr})\end{array}$ & $\begin{array}{l}\text { anaesthesia } \\
\text { duration } \\
(\text { min })\end{array}$ & $\begin{array}{l}\text { fentanyl } \\
\text { dose } \\
\left(\mu g \cdot \mathrm{kg}^{-1}\right)\end{array}$ \\
\hline $\begin{array}{l}\text { Isoflurane } \\
(\mathrm{n}=15)\end{array}$ & $9 / 6$ & $66 \pm 14$ & $51 \pm 10$ & $304 \pm 91$ & $608 \pm 223$ \\
$\begin{array}{l}\text { Desflurane } \\
(\mathrm{n}=15)\end{array}$ & $9 / 6$ & $63 \pm 17$ & $50 \pm 14$ & $292 \pm 63$ & $582 \pm 217$ \\
\hline
\end{tabular}

Mean \pm SD. No difference between groups.

TABLE II Recovery time after discontinuation of the inhaled agent (min). Results are expressed in Mean \pm SD (range).

\begin{tabular}{llll}
\hline & $\begin{array}{l}\text { Isoflurane } \\
(n=15)\end{array}$ & $\begin{array}{l}\text { Desflurane } \\
(n=15)\end{array}$ & $P$ \\
\hline $\begin{array}{l}\text { Open eyes } \\
\begin{array}{l}\text { Squeeze fingers at } \\
\text { command }\end{array}\end{array}$ & $24 \pm 11(9-45)$ & $12 \pm 7^{\star}(5-31)$ & 0.001 \\
$\begin{array}{l}\text { Tracheal extubation } \\
\text { Give name at }\end{array}$ & $33 \pm 19(16-80)$ & $17 \pm 11^{*}(6-44)$ & 0.004 \\
$\quad$ command & $43 \pm 21(19-58)$ & $16 \pm 6^{*}(7-24)$ & 0.001 \\
Steward score at 6 & $57 \pm 33(20-150)$ & $22 \pm 11^{*}(8-52)$ & 0.002 \\
\hline
\end{tabular}

* different from isoflurane group

TABLE III Tympanic temperature at the start of surgery and on arrival in the recovery room, occurence, severity and duration of shivering during recovery after desflurane and isoflurane anaesthesia.

\begin{tabular}{lll}
\hline & $\begin{array}{l}\text { Isoflurane } \\
(n=15)\end{array}$ & $\begin{array}{l}\text { Desflurane } \\
(n=15)\end{array}$ \\
\hline Tymp Temp $\left({ }^{\circ} \mathrm{C}\right)$ start of surgery & $36.9 \pm 0.5$ & $36.7 \pm 0.4$ \\
Tymp Temp $\left({ }^{\circ} \mathrm{C}\right)$ recovery room & $36.3 \pm 1.0$ & $36.0 \pm 1.3$ \\
shivering occurence $(\mathrm{n})$ & 7 & 6 \\
severity of shivering $+/++$ & $4 / 3$ & $3 / 3$ \\
duration of shivering (min) & $7.9 \pm 11$ & $\mathbf{3 . 9} \pm 7$ \\
\hline
\end{tabular}

Mean $\pm S D$. No difference between groups.

$+=$ moderate shivering (electrocardiographic diagnosis)

$++=$ severe shivering (clinical diagnosis)

Using meta analysis of previous comparisons between desflurane and isoflurane, Dexler et al. pooled studies with different patients and different anaesthesia regimens. They concluded that desflurane lead to a faster recovery than isoflurane, but the difference $(4.4 \mathrm{~min}$ ) was of only minor clinical importance. ${ }^{20}$ However, all these studies were undertaken in short duration procedure. Only one previous study compared recovery times of desflurane and isoflurane after prolonged exposure (239 $\mathrm{min}$ and $290 \mathrm{~min}$ for desflurane and isoflurane respectively). ${ }^{25}$ Responses to verbal commands did not differ between the two groups and was effective at $22 \pm$ $15 \mathrm{~min}$ and $23 \pm 14 \mathrm{~min}$ after discontinuation of desflurane and isoflurane respectively. Anaesthetic agents were stopped at the start of parietal wall closure. This was sometimes well before the end of the procedure and 
anaesthesia was then maintained with nitrous oxide until the end of skin closure. The time between halogenated agents and nitrous oxide discontinuation was unknown and no comparative tests of these data were applied. Although this methodology corresponds to common clinical practice, the lack of uniformity in the study design could be an explanation of the discrepancies with our conclusions. In our study, halogenated agents were stopped concurrently to nitrous oxide in all patients at the end of surgical procedure. Furthermore, in Azad's study, recovery was assessed only as the time until patients responded to verbal commands. No information was given for time to extubation. In our study, we focused on immediate and intermediate recovery parameters. Steward score evaluates grade of consciousness, ability to maintain airway and moving. ${ }^{22}$ This score had been chosen because it is easy to perform and it represents a series of progressive changes directly related to the recovery process. Rapid initial recovery may increase airway protection after tracheal extubation in the recovery room. Improving intermediate recovery parameters (such as response to command and the ability to talk) is also of major importance because, at this time, patients are often less supervised and good awakening could lead to improved management of the postoperative period (e.g., better evaluation of postoperative pain). In addition to faster recovery, we demonstrated less variability of the time to awakening in the desflurane group. Better predictability of recovery after long lasting anaesthesia could be consider as a safety argument for desflurane.

Halogenated anaesthetic consumption during the procedure may influence the time to recovery. Total consumption, estimated by the area under the curve of end-tidal concentration throughout the course of the procedure, expressed as MAC fraction, was less with desflurane than with isoflurane. Halogenated end-tidal concentrations were adjusted to obtain an adequate level of anaesthesia and blood pressure stability. Haemodynamic profiles were similar between the two groups. Moreover, the effects of fentanyl on the reduction of halogenated MAC are similar for desflurane and isoflurane. ${ }^{26}$ Explanations of the difference in consumption are unclear. As the MAC value decreases with age, especially for desflurane, it is possible that MAC in the patients over 65 years old have been a little overestimated and misled our results. Nevertheless, it is unlikely that such difference in anaesthetic consumption could explain our results. Furthermore, at the time we stopped halogenated administration, end-tidal concentration, converted to fractional MAC, did not differ between the two groups. Both received the same doses of fentanyl and residual neuromuscular blockade was antagonised if needed.
It has been suggested that rapid elimination of halogenated agent may increase the occurence and severity of shivering, secondary to the sudden recovery of thermoregulatory mechanisms. ${ }^{27}$ In our study, intraoperative heat loss was reduced with forced-air warming blankets. Only half the patients experienced shivering, which was always of short duration. No difference was observed between desflurane and isoflurane concerning the occurence, duration and severity of shivering.

Time to be fitness for discharge from the recovery room was faster with desflurane than with isoflurane. Time for effective discharge was similar, probably because of extra-anaesthetic factors. One explanation is that the fast recovery obtained with the new agent desflurane was unusual for the recovery room nursing team who were blinded to the agent used. Cost-saving relative to the potential ability to decrease the stay in recovery room with desflurane should be compared with the greater expenditure relative to its administration. Lowflow anaesthesia is recommended during long lasting administration of halogenated agents and has been estimated to provide important reduction of anaesthetic consumption. ${ }^{28}$

In conclusion, prolonged anaesthesia of more than three hours highlights the pharmacodynamic properties of desflurane. Recovery parameters, extubation and time to fitness for discharge from the recovery room with desflurane were approximatively half those with isoflurane. In addition, the variability of times to awakening in the desflurane group was less than with isoflurane, suggesting that recovery is more predictable with desflurane.

\section{Appendix I}

\section{Lorentz formula}

Ideal weight for men $(\mathrm{kg})=$ height $(\mathrm{cm})-100 \frac{- \text { height }-150}{4}$

Ideal weight for women $(\mathrm{kg})=$ height $(\mathrm{cm})-100-$ height -150

\section{Appendix II}

\section{Stewpard score}

Consciousness

Awake

2

Reponding to stimuli

Not reponding

1

Airway

Coughing on command or crying 2

Maintening good airway

Airway requires maintenance

Movement

Moving limbs purposefully

Non-purposeful movements

Not moving 


\section{References}

1 Eger EI II. Partition coefficients of I-653 in human blood, saline, and olive oil. Anesth Analg 1987; 66: 971-3.

2 Eger EI II. Uptake of inhaled anesthetics. The alveolar to inspired anesthetic difference. In: Eger EI II (Ed.). Anesthetics Uptake and Action. Baltimore: Williams and Wilkins, 1974: 77-97.

3 Lockhart SH, Cohen Y, Yasuda N, et al. Cerebral uptake and elimination of desflurane, isoflurane, and halothane from rabbit brain: an in vivo NMR study. Anesthesiology 1991; 74: 575-80.

4 Eger EI II, Jonbson BH. Rates of awakening from anesthesia with I-653, halothane, isoflurane and sevoflurane: a test of the effect of anesthetic concentration and duration in rats. Anesth Analg 1987; 66: 977-82.

5 Yasuda N, Lockbart SH, Eger EI II, et al. Kinetics of desflurane, isoflurane, and halothane in humans. Anesthesiology 1991; 74: 489-98.

6 Ghouri AF, Bodner M, White PF. Recovery profile after desflurane-nitrous oxide versus isoflurane-nitrous oxide in outpatients. Anesthesiology 1991; 74: 419-24.

7 Smiley RM, Ornstein E, Matteo RS, Pantuck EJ, Pantuck $C B$. Desflurane and isoflurane in surgical patients: a comparison of emergence time. Anesthesiology 1991; 74: 425-8.

8 Wrigley SR, Fairfield JE, Jones RM, Black AE. Induction and recovery characteristics of desflurane in day case patients: a comparison with propofol. Anaesthesia 1991; 46: 615-22.

9 Van Hemelrijck J, Smith I, White PF. Use of desflurane for outpatient anesthesia. A comparison with propofol and nitrous oxide. Anesthesiology 1991; 75: 197-203.

10 Fletcher JE, Sebel PS, Murphy MR, Smith CA, Mick SA, Flister MP. Psychomotor performance after desflurane anesthesia: a comparison with isoflurane. Anesth Analg 1991; 73: 260-5.

11 Bennett JA, Lingaraju N, Horrow JC, McElrath T, Keykbah $M M$. Elderly patients recover more rapidly from desflurane than from isoflurane anesthesia. J Clin Anesth 1992; 4: 378-81.

12 Smiley RM. An overview of induction and emergence characteristics of desflurane in pediatric, adult, and geriatric patients. Anesth Analg 1992; 75: S38-46.

13 Taylor RH, Lerman J. Induction, maintenance and recovery characteristics of desflurane in infants and children. Can J Anaesth 1992; 39: 6-13.

14 Tsai SK, Lee C, Kwan W-F, Chen B-J. Recovery of cognitive functions after anaesthesia with desflurane or isoflurane and nitrous oxide. $\mathrm{Br} J$ Anaesth 1992; 69: 255-8.

15 Rapp SE, Conaban TJ, Pavlin DJ, et al. Comparaison of desflurane with propofol in outpatients undergoing peripheral orthopedic surgery. Anesth Analg 1992; 75: 572-9.
16 Kelly RE, Hartman GS, Embree PB, Sharp G, Artusio JF $J r$. Inhaled induction and emergence from desflurane anesthesia in the ambulatory surgical patient: the effect of premedication. Anesth Analg 1993; 77: 540-3.

17 Lebenbom-Mansour MH, Pandit SK, Kothary SP, Randel GI, Levy L. Desflurane versus propofol anesthesia: a comparative analysis in outpatients. Anesth Analg 1993; 76: 936-41.

18 Grabam SG, Aitkenbead AR. A comparison between propofol and desflurane anaesthesia for minor gynaecological laparoscopic surgery. Anaesthesia 1993; 48: 471-5.

19 Loan PB, Mirakbur RK, Paxton LD, Gaston JH. Comparison of desflurane and isoflurane in anaesthesia for dental surgery. Br J Anaesth 1995; 75: 289-92.

20 Dexter F, Tinker JH. Comparisons between desflurane and isoflurane or profofol on time to following commands and time to discharge. A metaanalysis. Anesthesiology 1995; 83: 77-82.

21 Camus $\Upsilon$, Delva E, Just B, Lienbart A. Leg warming minimizes core hypothermia during abdominal surgery. Anesth Analg 1993; 77: 995-9.

22 Steward DJ. A simplified scoring system for the postoperative recovery room. Can Anaesth Soc J 1975; 22: 111-3.

23 Eger EI II. Isoflurane: a review. Anesthesiology 1981; 55: 559-76.

24 Eger EI II. Desflurane animal and human pharmacology: aspects of kinetics, safety, and MAC. Anesth Analg 1992; 75: S3-9.

25 Azad SS, Bartkowski RR, Witkowski TA, Marr AT, Lessin JB, Seltzer JL. A comparison of desflurane and isoflurane in prolonged surgery. J Clin Anesth 1993; 5: $122-8$.

26 Ghouri $A F$, White $P F$. Effects of fentanyl and nitrous oxide on the desflurane anesthetic requirement. Anesth Analg 1991; 72: 377-81.

27 Ciofolo MJ, Clergue F, Devilliers C, Ben Ammar M, Viars $P$. Changes in ventilation, oxygen uptake, and carbon dioxide output during recovery from anesthesia. Anesthesiology 1989; 70: 737-41.

28 Deriaz $H$, Duranteau $R$, Delva E, Lienhart A. Compared consumption of three volatile anesthetics (isoflurane, sevoflurane, desflurane) in simulated anesthesia. Anesthesiology 1995; 83: Al039. 